\title{
Methods for the construction of lowered structures and pile foundations
}

\author{
Vladimir Kocherzhenko and Lyudmila Suleymanova* \\ Belgorod State Technological University named after V.G. Shukhov, 308012, Belgorod, Russian \\ Federation
}

\begin{abstract}
The paper discusses the methods of erecting sunk wells and pile foundations, which consist in regulating the frictional forces of soils: lowering along the lateral surface when sinking wells and increasing when erecting pile foundations. The developed method of sinking wells provides for the application of two types of effective antifriction coatings along the lateral surface: along the cutting edge of the structure and above the cutting ledge. At the same time, the coefficients of reducing the friction forces by these coatings for various types of soils have been established, and a method for calculating sunk wells for lowering is proposed, taking into account the use of the developed submerging method. To increase the friction forces on the lateral surface of the driven piles and to increase their bearing capacity, modular piles with a developed lateral surface of the Tsection have been developed and introduced. The areas of rational use of these piles are established depending on the types of soils (clay and sandy) and the depth of their penetration.
\end{abstract}

\section{Introduction}

In underground construction and in pile foundation construction, soil friction often has both a positive and a negative effect on the bearing capacity of structures. When erecting deep underground structures using a sunk well method, friction forces along the lateral surface play a negative role, since they prevent the structure from sinking to the design level. In pile foundation construction, friction forces along the lateral surface of piles play a positive role, since they allow increasing the bearing capacity of the pile foundation. Therefore, the development of methods for regulating the forces of external friction of soils in underground and pile foundation construction is very relevant.

In modern construction of lowered structures, to reduce the external friction of soils during their lowering, the following is used: thixotropic jacket [1-3], vibration penetration $[4,5]$, electro osmosis [6] and other methods. The authors studied and introduced a method for reducing the frictional force of soils along the lateral surface of wells using antifriction coatings. In this case, two types of coatings were taken into account: for conditions of close contact of the soil with the cutting edge of the well (based on wear-resistant film-forming substances -ethynol varnish, resins, etc.) and self-lubricating coatings for conditions of

*Corresponding author: ludmilasuleimanova@yandex.ru 
loose contact of the soil with the side surface above the cutting ledge (based on bottoms of synthetic fatty acids (B SFA) [7].

Anti-friction coatings have been developed for sandy and clayey soils. To improve the antifriction properties of coatings, three types of additives were introduced into the starting materials: modifying, technological, and antifriction. Considering that the antifriction characteristics of coatings depend on its composition, i.e. on the percentage of its components, the optimal compositions of these coatings for sinking wells in sandy and clayey soils have been established. The search for the optimum was carried out using the second-order orthogonal planning technique [8].

The degree of reduction of the external friction coefficient using an anti-friction coating was taken as an optimization parameter. Based on the results of the experiments, the coefficients of the regression equations were calculated, their significance was checked, significant coefficients were identified, and the regression equations were obtained. The study of the obtained mathematical models in the form of second degree polynomials showed that they adequately describe the real processes of soil friction against coatings.

\section{Materials and Methods}

In order to determine the optimal compositions of antifriction coatings, the extrema of the functions are found by taking partial derivatives and equating them to zero. The obtained optimal content of components in the compositions of antifriction coatings for the cutting edge of the well above the ledge and the averaged coefficients of reducing the friction force of clay and sandy soils relative to the concrete surface are presented in table 1.

Table 1. Optimal compositions of antifriction coatings and the degree of reduction of the coefficients of external friction of soils

\begin{tabular}{|c|c|c|c|c|c|}
\hline \multirow{3}{*}{$\begin{array}{l}\text { Scope of } \\
\text { using the } \\
\text { coating }\end{array}$} & \multirow{3}{*}{$\begin{array}{l}\text { Type of } \\
\text { antifriction } \\
\text { coating }\end{array}$} & \multirow{3}{*}{$\begin{array}{l}\text { Component } \\
\text { name }\end{array}$} & \multirow{2}{*}{\multicolumn{2}{|c|}{$\begin{array}{l}\text { Content of } \\
\text { components in } \\
\text { the coating (\% by } \\
\text { weight) } \\
\text { Soil types }\end{array}$}} & \multirow{3}{*}{$\begin{array}{l}\text { Coefficient of } \\
\text { reducing the } \\
\text { friction force } \\
\text { relative to the } \\
\text { concrete } \\
\text { surface }(\mathrm{K})\end{array}$} \\
\hline & & & & & \\
\hline & & & Clay & $\begin{array}{l}\text { Fine } \\
\text { sand }\end{array}$ & \\
\hline $\begin{array}{l}\text { By the } \\
\text { cutting } \\
\text { edge of } \\
\text { the well }\end{array}$ & $\begin{array}{l}\text { Based } \\
\text { ethynol } \\
\text { varnish }\end{array}$ & $\begin{array}{l}\text { Ethynol } \\
\text { varnish } \\
\text { Latex SKS- } \\
65 \\
\text { Turpentine } \\
\text { Graphite } \\
\end{array}$ & $\begin{array}{l}56.0 \\
16.0 \\
14.0 \\
14.0\end{array}$ & $\begin{array}{l}56.0 \\
16.0 \\
12.0 \\
16.0\end{array}$ & $\begin{array}{l}\left(\mathrm{K}_{1}\right) \\
0.70-0.75\end{array}$ \\
\hline $\begin{array}{l}\text { Above the } \\
\text { cutting } \\
\text { ledge }\end{array}$ & $\begin{array}{l}\text { Based on B } \\
\text { SFA }\end{array}$ & $\begin{array}{l}\text { B SFA } \\
\text { BN-IV } \\
\text { bitumen } \\
\text { SFA } \\
\text { Talc }\end{array}$ & $\begin{array}{l}57.0 \\
4.0 \\
35.0 \\
4.0\end{array}$ & $\begin{array}{l}57.0 \\
8.0 \\
31.0 \\
4.0\end{array}$ & $\begin{array}{l}\left(\mathrm{K}_{2}\right) \\
0.4-0.45\end{array}$ \\
\hline
\end{tabular}

To introduce the method of reducing the friction force using antifriction coatings into construction practice, a method has been developed for calculating the friction of soils along the lateral surface during lowering. In this case, it was assumed that the total friction force along the lateral surface of the well is made up of friction along the cutting edge and above the ledge:

$$
\sum T=T_{\mathrm{c}}+T_{\mathrm{a} .1}
$$


It is recommended to calculate the friction of the cutting edge surface through the specific friction force $t_{\mathrm{c}}$, determined by $[2,9]$ :

$$
T_{\mathrm{c}}=t_{\mathrm{c}} \cdot F_{\mathrm{c}},
$$

where $t_{c}$ - specific force of soil friction along the cutting edge; $F_{c}$ - lateral surface area of the cutting edge.

Specific friction force above the ledge $t_{\text {a.l. }}$ is recommended to determine as the ratio of the friction force above the ledge $T_{\text {a.l. }}$ to the area of the lateral surface above the ledge $F_{\text {a.l. }}$ :

$$
t_{\text {a.l. }}=\frac{T_{a . l .}}{F_{\text {a.l. }}}=\frac{\sum T-T_{c}}{F_{a . l .}}
$$

The total friction force along the shell of the gravity well is [10]:

$$
\sum T=t_{f p} \cdot U\left(H_{w}-1.5\right),
$$

where $t_{f p}$ - specific friction force of soils on the shell of a gravity well; $U$ - outer perimeter of the well shell; $H_{w}$ - well sinking depth.

Then from (3):

$$
t_{\text {a.l. }}=\frac{t_{f p} U\left(H_{w}-1.5\right)-t_{c} F_{c}}{F_{\text {a.l. }}}
$$

When using antifriction coatings of two types (on the cutting edge - based on ethynol varnish, above the ledge - based on B SFA), the friction force on the side surface of the well is determined by the above formulas, taking into account the coefficients of reducing friction $K_{1}$ and $K_{2}$ [11].

\section{Results and discussions}

An increase in the frictional force of soils along the lateral surface of the piles is achieved in two ways: increasing the specific frictional force of the soil or increasing the area of the lateral surface of the pile.

There are several design and technological solutions for piles with a developed lateral surface: triangular, three-lobed, cruciform and others $[12,13]$. The authors have developed, studied and introduced into construction practice modular T-section piles, which, with equal concrete consumption with square piles, have a 2.2...2.5 times larger lateral surface area [14-16]. To select and improve the rational cross-section of piles, the dependence of the consumption of reinforced concrete for piles of various cross-sections on the depth of penetration in clay and sandy soils was establishedusing the software. The results are shown in figure 1.

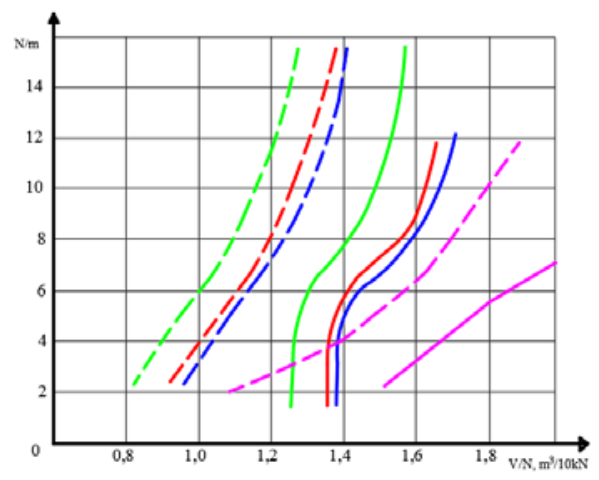


Fig. 1. Dependence of the specific consumption of reinforced concrete piles with a cross section of $30 \times 30 \mathrm{~cm}$ on the depth of penetration in clay soils with a consistency index $\left(I_{L}\right)=0.5$ (solid line) and sandy (medium-sized sand, medium density): triangular section; - T-section; - three-lobed section;

According to the results obtained (fig. 1), the most rational cross-section of driven suspended piles is T-section, since compared to other cross-sections, the specific consumption of reinforced concrete for a given pile cross-section is $15-20 \%$ less.

In order to determine the area of rational use of T-section piles, the driving depth was established, at which the bearing capacity is determined by friction, i.e. the friction forces along the lateral surface exceed the resistance of the soil under the pile tip. The dependence of the ratio of the friction force to the resistance of the soil under the tip of T-section piles is determined(height $-30 \mathrm{~cm}$, shelf width $-30 \mathrm{~cm}$, wall $-10 \mathrm{~cm}$, shelf $-10 \mathrm{~cm}$ ). Calculations are made for sandy and clayey soils. The resulting dependences for soils are shown in figure 2 .

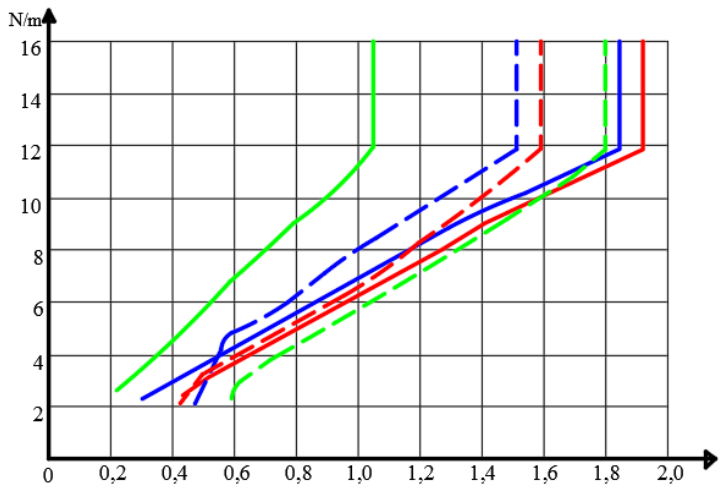

Fig. 2. Dependence of the ratio of friction forces on resistance under the tip of piles with $d=30, d_{l}=$ $10, d_{2}=10$ when penetrated in silty clay soils $I_{L}=0.5$ (solid lines) and in sands of medium size and average density (dotted lines):__ $-\mathrm{T}$-section;__ - triangular section; __ - square section.

The research results presented in figure 2 , indicate that in silty-clayey soils with $I_{L}=$ 0.5 , the bearing capacity of T-section piles with a driving depth $H>9.0 \mathrm{~m}$ is mainly formed by the friction force, since $T / R>1.0$. In sands of medium size and average density, the bearing capacity of T-section piles is formed mainly by the friction force at a driving depth $H>10.0 \mathrm{~m}$. Therefore, it is rational to use T-section piles at a significant driving depth, which requires the piles to be joined in depth. The appearance of prefabricated reinforced concrete piles of T-section and their joints in depth during driving are shown in figure 3.

a)

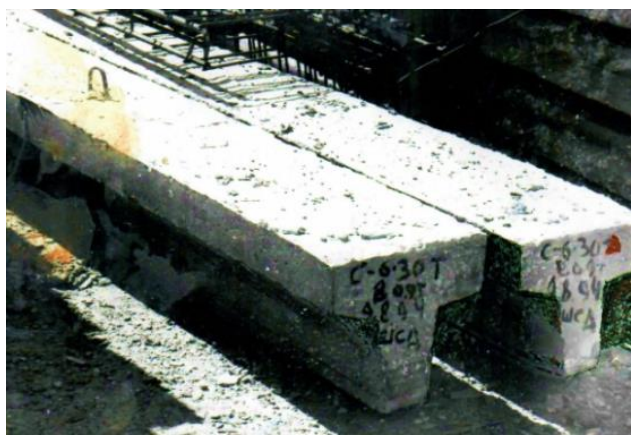

b)

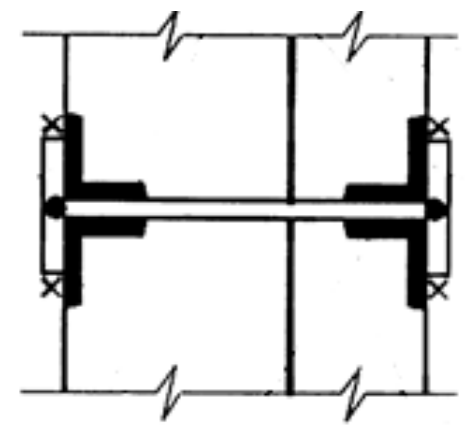

Fig. 3. T-sections: $a$ - appearance of precast reinforced concrete piles; $b$ - junction point of piles in depth when driving 
The T-section is a figure that can be successfully assembled in plan as a modular element in the design of pile foundations. Figure 4 shows the possible options for the layout of pile foundations from modular T-section piles and an example of the layout of the foundation under the action of a complex combination of loads.

a)

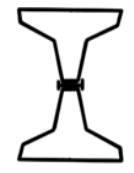

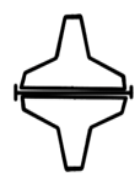
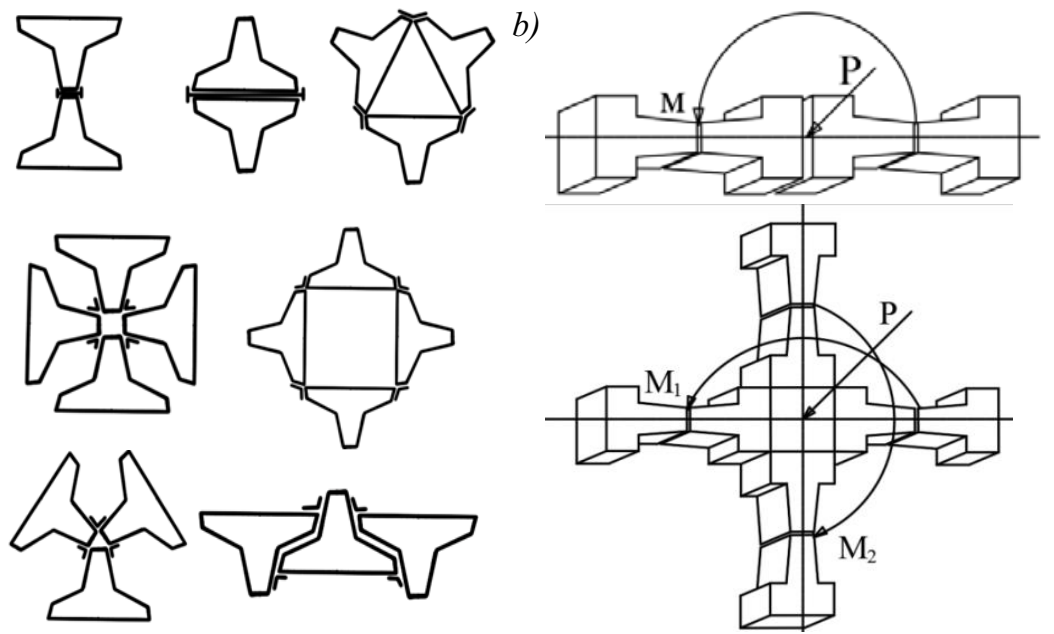

Fig. 4. Modular pile foundations: $a$ - options for the arrangement of foundations based on modular piles; $b$ - an example of a layout under the action of a complex combination of loads

\section{Conclusions}

As a result of the development of methods for regulating the forces of external friction of soils during the sinking of lowered structures and piles, the authors have developed and introduced into construction practice wear-resistant antifriction coatings: on the cutting edge- based on ethynol varnish, and above the ledge - self-lubricating coatings based on bottoms of synthetic fatty acids. At the same time, coefficients of reducing friction by these coatings for clay and sandy types of soils in their various states have been established. A method is proposed for calculating lowered structures for sinking, taking into account the use of antifriction coatings.

To increase the bearing capacity of driven piles by increasing the area of their lateral surface, it was established that the T-section is a rational cross-section of driven piles. It is rational to use these piles in silty-clayey soils with $I L=0.5$ at a driving depth $H>9.0 \mathrm{~m}$, in sands of medium coarseness and average density - at a driving depth $H>10.0 \mathrm{~m}$.

Options for the arrangement of pile foundations based on modular T-section piles are presented, including for cases of a complex combination of loads on the foundation.

\section{References}

1. V.L. Kotov, V.V. Balandin and A.K. Lomunov, Assessing the Effects of Surface Friction in Non-Stationary Contact of Structural Elements with Sand SoilProblems of Strength and Plasticity, National Research Lobachevsky State University of Nizhni Novgorod (UNN) 72(1) 137-41 (2010).

2. V.V. Kocherzhenko and I.A. Pogorelova, Research of Influence of Technology of Immersion of Shells of Sunk Wells in Their Mode of Deformation, Bulletin of Belgorod State Technological University named after V G Shukhov 2(1) 65-72 (2016). 
3. Z-D Cui, Z-L Zhang, L Yuan, Z-X Zhan and W-K Zhang, Design of Immersed Tube Structures Design of Underground Structures Springer Singapore 553-92 (2019).

4. F.B. Chen, Experimental Study on the Effect of Vibration of Pile Foundation Construction, Applied Mechanics and Materials.Trans Tech Publications, Ltd. 711 392-6 (2014).

5. A.O.K. and V.N.P., Experimental Research of the Pile-Cap Deepening at the Vibration of a Pile Foundation, Modern Methods and Advances in Structural Engineering and Construction (ISEC-6) Research Publishing Services (2011).

6. Y. Cao, J. Yang and D. Cheng, Large Scale Test on Improving Ultra Soft Soil Using Electro-Osmotic Method Ground Improvement and Geosynthetics, American Society of Civil Engineers (2010).

7. L.A. Suleymanova, V.V. Kocherzhenko and N.V. Solodov, Improvement of Organizational and Technological Decisions of the Process of Sinking the Sunk Structures Construction production 2 13-9 (2019).

8. Planning an Experiment Grow: Plant Health Exchange, Scientific Societies (2008).

9. S.H. Chan, Negative Skin Friction on Piles in Consolidating GroundThe Hong Kong University of Science and Technology Library

10. Computer-Support for the Design of Underground StructuresTechnology Innovation in Underground Construction CRC Presspp 55-74 (2009).

11. B. Yun, Design of Underground Structures Underground Engineering, Elsevier 47-115 (2019).

12. F. Tian and D. Bai, Construction Design and Maintenance Measures for Underground Concrete Construction, ISME 2016 - Information Science and Management Engineering IV SCITEPRESS - Science and and Technology Publications (2016).

13. D. Holloway, G. Clough and A.A. Vesic, Rational Procedure for Evaluating the Behavior of Impact-Driven Piles Behavior of Deep Foundations, ASTM International 335-335-23.

14. M.A. Wong, Study Of Capacity Predictions For Driven Piles by Dynamic Pile Testing, The University of Hong Kong Libraries.

15. T.V. Ivanova, I.U. Albert, B.D. Kaufman and S.G. Shulman, The Load-Bearing Capacity of Hanging Piles by the Strength Criterion of a Pile or Soil Material Magazine of Civil Engineering, Saint Petersburg State Polytechnical University 67 (07) 3-12 (2017). 